\title{
O Papel dos Modelos Computacionais e das Analogias na Aprendizagem do Processo de Interação Fármaco-Enzima no Ensino Fundamentado em Modelagem
}

\section{The Role of Computational Models and Analogies in Learning the Drug-Enzyme Interaction Process in Modelling-Based Teaching}

\author{
Diego Magno Martins \\ Nilmara Braga Mozzer \\ Thais Mara Anastácio Oliveira \\ Brasil \\ Brasil \\ Melissa Soares Caetano \\ Brasil \\ Brasil
}

Neste trabalho, investigamos os papéis desempenhados pelos modelos computacionais e pelos processos de crítica e elaboração de analogias na compreensão conceitual do processo de interação fármaco-enzima. A investigação ocorreu com licenciandos do quinto período de um curso de Química ao vivenciarem um processo de ensino fundamentado na modelagem. As aulas foram filmadas e os materiais escritos produzidos pelos estudantes recolhidos. A análise desses materiais fundamentou a elaboração de um estudo de caso que nos permitiu evidenciar que a representação do sistema pelos modelos computacionais possibilitou que os estudantes desenvolvessem uma maior compreensão do conceito alvo, devido à visualização da disposição espacial dos átomos em macromoléculas e ao tratamento dinâmico desse tipo de sistema. Essa compreensão foi manifestada, principalmente, nos processos de crítica e criação de analogias. Por isso, realçamos a importância de que os licenciandos tenham experiências que os permitam refletir sobre as potencialidades e as limitações dos diferentes recursos de expressão de modelos ao vivenciarem processos de modelagem durante sua formação. Defendemos também a realização de novas investigações sobre a compreensão dos estudantes acerca da natureza dos modelos computacionais e das analogias nestes processos.

Palavras-chave: modelos computacionais; analogias; interação fármaco-enzima; ensino fundamentado em modelagem.

In this study, we investigate the roles played by computational models and by the processes of criticism and elaboration of analogies in the conceptual understanding of the drug-enzyme interaction process. The study took place with pre-service teachers who were attending the third year of a Chemistry course when they experienced a 
teaching process based on modelling. The classes were filmed and the written materials produced by the students were collected. The analysis of these materials supported the development of a case study that allowed us to show that the representation of the system by computational models enabled students to develop a greater understanding of the target concept, due to the visualization of the spatial arrangement of atoms in macromolecules and the dynamic treatment that type of system. This understanding was mainly manifested in the processes of criticism and creation of analogies. For this reason, we emphasise the importance of pre-service teachers having experiences that allow them to reflect on the potential and limitations of the different model expression resources when experiencing modelling processes during their education. We also highlight the need of carrying out new investigations on students' understanding of the nature of computational models and analogies in these processes.

Keywords: computational models; analogies; drug-enzyme interaction; modellingbased teaching.

\section{Introdução}

Como poderíamos descrever ou explicar o funcionamento das células, as reações químicas ou o movimento dos continentes sem fazer o uso de modelos? Tarefa impossível! Isso porque, se considerarmos como Gilbert e Justi (2016), apoiados no trabalho de Knuuttila (2005), que os modelos são artefatos humanos que apoiam o pensamento, os quais são materializados de alguma maneira que favoreça a sua manipulação em diferentes práticas epistêmicas, a construção e o emprego de modelos são processos fundamentais tanto na pesquisa científica, quanto na aprendizagem de Ciências (Gilbert \& Justi, 2016; Harrison \& Treagust, 2000).

A relevância dos modelos na ciência e no ensino de Ciências justifica-se ao considerarmos que a criação e a utilização de modelos fazem parte do processo natural de elaboração de conhecimentos pelo ser humano (Johnson-Laird, 1983). No entanto, o grau de complexidade com que estas ferramentas são empregadas varia em função do contexto e da expertise de quem os propõe. Por exemplo, na ciência, os modelos são usados pelos cientistas de vários modos pragmáticos, como ferramentas que os ajudam a compreender o mundo. Já no ensino de Ciências, o uso e manipulação de modelos possibilita a aprendizagem, uma vez que podem apoiar a imaginação sobre como as entidades (objetos, fenômenos, processos e ideias) podem ser, comportar-se ou interagirem entre si (Coll et al., 2005; Grosslight et al.,1991).

A aprendizagem no ensino de Ciências é mediada pelos diferentes tipos de modelos (Gilbert, 2004): modelos mentais, os quais são representações internas e pessoais do sistema alvo modelado; modelos expressos, que são representações externas do alvo, gerados por meio da expressão dos modelos mentais; modelos consensuais, que derivam de modelos expressos desenvolvidos, testados e acordados por cientistas (neste caso, chamados modelos cientificos) ou por grupos de estudantes; modelos curriculares, que 
são simplificações dos modelos científicos; e modelos de ensino, que são desenvolvidos e utilizados pelos professores e desenvolvedores de materiais didáticos para promover a compreensão de um determinado aspecto de um modelo curricular.

No caso específico dos modelos de ensino, estes podem desempenhar um papel importante na aprendizagem de Ciências, considerando-se que, muitas vezes, as entidades de estudo da ciência são abstratas e de difícil compreensão para os estudantes. Entre eles, as analogias ganham destaque por facilitarem a compreensão de conceitos científicos a partir da comparação destes com algo já conhecido pelos estudantes. Para além desta potencialidade, quando as analogias são utilizadas de maneira conjunta com o processo de modelagem (processo de produção, expressão, teste e avaliação de modelos), elas podem favorecer o desenvolvimento de habilidades e compromissos epistemológicos dos estudantes (Mozzer, \& Justi, 2018; Oliva, \& Aragón, 2009).

Assim, considerando a relevância dos modelos na ciência e no ensino de Ciências, neste trabalho, buscamos investigar o desenvolvimento do entendimento conceitual de licenciandos em Química sobre o processo de inibição de uma enzima por um fármaco, ao longo de uma sequência de ensino fundamentada na modelagem. Mais especificamente, nos propusemos a responder a seguinte questão de pesquisa: como os modelos computacionais e os processos de crítica e de elaboração de analogias contribuíram para a compreensão conceitual sobre o tema?

\section{Analogias, modelos e modelagem no ensino de Ciências}

É comum utilizarmos analogias, principalmente quando encontramos dificuldade de explicar algo. Isso porque, elas podem facilitar a compreensão do que se deseja explicar a partir da comparação com algo que já é conhecido pelos sujeitos (Coll, 2006). De acordo com Gentner (1983), nesse tipo de comparação, relações de similaridade são estabelecidas entre um domínio familiar, denominado base (ou análogo) e outro não familiar ou pouco familiar, denominado alvo. Essa autora, denomina mapeamento o processo de estabelecimento das correspondências entre as relações de similaridade.

Analogias e modelos são empregados frequentemente nas aulas de Ciências, principalmente quando deseja-se favorecer a comunicação de ideias científicas, favorecer a compreensão destas pelos estudantes, facilitar a visualização de entidades abstratas, entre outros objetivos (Coll, 2006; Justi, 2019; Mozzer \& Justi, 2015).

Apesar das analogias serem utilizadas corriqueiramente em aulas de Ciências, estudos como os de Duit (1991) e Orgill e Bodner (2004) apontam que a forma como elas vêm sendo trabalhadas no ensino têm promovido o seu uso irrefletido pelos estudantes. Exemplos dessas incompreensões são os fatos de, frequentemente, eles: mencionarem apenas o domínio análogo de uma comparação como se este falasse por si só; não conseguirem relacionar o domínio análogo com o alvo; desenvolverem um conhecimento superficial sobre o domínio alvo; e não compreenderem que existem aspectos em que o análogo se difere do alvo em uma analogia (limitações da analogia).

De forma similar, trabalhos como o de Justi (2019) e de Treagust, Chittleborough 
e Mamiala (2004) demonstram que muitos estudantes apresentam concepções inadequadas sobre a natureza dos modelos, como: vê-los como uma cópia da realidade; acreditar que só há um modelo possível para uma determinada entidade; e pensar que o valor de um modelo é determinado pela opinião dos cientistas, e não pelas evidências que o apoiam.

Tais problemas podem ser superados quando o uso passivo dos modelos dá lugar a um processo ativo, no qual os estudantes propõem, avaliam e revisam modelos (Chittleborough, \& Treagust, 2009). Já no que se refere às analogias, muitos dos problemas mencionados anteriormente podem ser mitigados se, tanto a apresentação de uma analogia pelo professor ou material instrucional, quanto a sua elaboração pelos estudantes for um processo guiado. No primeiro caso, o mapeamento das relações analógicas e a discussão das limitações da analogia devem ser realizados com os estudantes. No segundo, o professor deve auxiliá-los no processo de identificação de correspondências e das limitações de suas comparações (Duit, 1991; Glynn, 1991; Mozzer \& Justi, 2015; Oliva \& Aragón, 2009).

Iniciativas que envolvem o processo de modelagem podem favorecer o uso adequado desses artefatos. Dentre elas, destaca-se o Ensino de Ciências Fundamentado na Modelagem proposto por Justi e Gilbert (2002) e aprimorado no trabalho de 2016 (Gilbert \& Justi, 2016). A modelagem é assumida pelos autores como um processo complexo e não linear, que envolve ciclos recorrentes de criação, expressão, teste e avaliação de modelos (vide representação do processo na Figura 1).

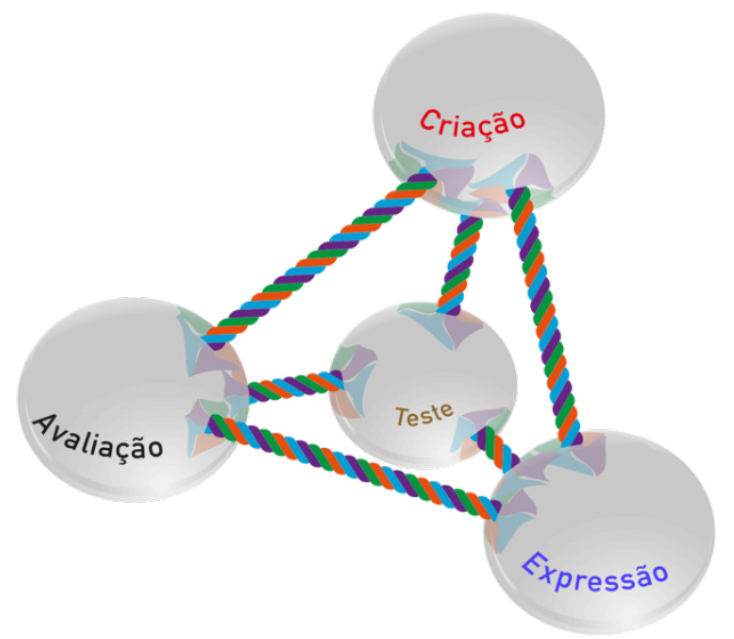

Figura 1. Diagrama Modelo de Modelagem v2 (Adaptada de Gilbert e Justi, (2016, p. 36))

Com base nos trabalhos de Justi (2006) e Gilbert e Justi (2016), as etapas da modelagem podem ser descritas da seguinte maneira:

- Criação: Na elaboração de um modelo é preciso definir ou compreender os objetivos do mesmo, ou seja, as diferentes finalidades para as quais ele será proposto. Definidos os objetivos, experiências com a entidade modelada (ou domínio alvo), provenientes de observações empíricas ou de informações 
sobre tal entidade, são necessárias. Simultaneamente à organização dessas experiências, ocorre a seleção da fonte do modelo - aspectos que serão usados para descrever a entidade modelada. Nesta etapa, a criatividade e o raciocínio crítico contribuem para a elaboração de um modelo inicial.

- Expressão: O modelo produzido precisa ser expresso em alguma forma de representação: o modo concreto, caracteriza-se pela utilização de materiais para a construção de um modelo tridimensional; o modo verbal, consiste na descrição por meio da fala e/ou da escrita da entidade que está sendo modelada; o modo simbólico, envolve as equações, fórmulas, equações matemáticas e outras representações que utilizam símbolos; o modo gestual, faz uso do corpo ou de suas partes para expressão do modelo; e o modo visual utiliza-se de gráficos, diagramas e animações.

- Teste: A etapa de teste consiste de verificações do modelo que podem ser de duas naturezas: experiências mentais ou testes experimentais. Em ambos os casos, se o modelo falhar em relação às previsões sobre o alvo, modificações devem ser feitas para que se possa reintegrá-lo no processo de modelagem. Em casos extremos, em que o teste indica problemas mais sérios, o modelo também pode ser rejeitado. Isto implicará numa reconsideração dos elementos da etapa de criação, levando-se em consideração o conhecimento adquirido até o momento.

- Avaliação: Quando um modelo tem êxito na etapa de teste, os modeladores que o desenvolveram se convencem de sua validade e sua próxima tarefa será convencer os outros indivíduos do mesmo. Neste processo de socialização, eles devem explicitar o alcance de validade do modelo (abrangência), bem como suas limitações em relação ao objetivo inicialmente definido e sua utilização em outros contextos.

A aprendizagem durante o processo de modelagem ocorre como resultado da evolução do entendimento conceitual através dos processos de elaboração, crítica e revisão de um ou mais modelos intermediários, até que seja alcançado um modelo mais coerente com as ideias científicas. O processo de reformulação de um modelo não é, geralmente, o resultado de uma grande e repentina mudança no modelo inicial, mas de muitos pequenos episódios de alterações. Muitas vezes, esse processo é iniciado quando o modelo não consegue explicar algum aspecto (um dado experimental, por exemplo), ou quando há uma dissonância entre um modelo proposto e uma dada evidência. Outro processo importante na evolução de um modelo ocorre quando aspectos que antes eram desconsiderados passam a compô-lo, ampliando o seu poder explicativo (Rea-Ramirez, Clement, \& Núñez-Oviedo, 2008).

Como parte do processo de modelagem, analogias também podem ser propostas, avaliadas e refinadas. Nesse processo, os estudantes criam suas próprias relações de 
similaridade visando compreender a entidade modelada. Neste sentido, as analogias podem funcionar como artefatos de pensamento, pois atuam como fontes de ideias na elaboração de modelos (Mozzer \& Justi, 2018).

O ensino de Ciências fundamentado em modelagem vai além da aprendizagem do conhecimento científico como um fim em si mesmo, integrando aprendizagens das práticas científicas e sobre como o conhecimento científico é produzido. Isso porque, ao vivenciarem processos semelhantes aos vivenciados pelos cientistas, os estudantes podem compreender o papel dos modelos e das analogias no desenvolvimento e divulgação do conhecimento científico, reconhecendo-os como artefatos de pensamento que lhes permite fazer explanações e propor explicações para as entidades estudadas (Coll et al., 2005; Justi, 2006; Mozzer \& Justi, 2018).

Embora não se restrinja à aprendizagem conceitual, o ensino fundamentado em modelagem tem se mostrado valioso no planejamento e desenvolvimento de atividades que contribuem para a evolução no entendimento conceitual dos estudantes, na medida em que eles: (i) discutem com os colegas e com o professor explicitando suas ideias e sendo questionados sobre elas; (ii) criam e expressam seus modelos e analogias; (iii) debatem estes com toda a turma, propondo reformulações a partir das evidências construídas/identificadas e dos questionamentos do professor; e (iv) identificam as limitações dos modelos e analogias (Maia \& Justi, 2009; Mozzer et al., 2007; Silva et al., 2017; Sousa \& Justi, 2010).

A vivência da modelagem em sala de aula é influenciada de maneira significativa pelas ações do professor, pois ele é o responsável por orientar as discussões e minimizar as dificuldades dos estudantes. Por meio de questionamentos e discussões, os professores possibilitam que os estudantes construam modelos e analogias de forma coerente com as ideias científicas, auxiliando-os na explicitação e explicação das ideias que fundamentam suas proposições e na reflexão sobre a abrangência e as limitações das mesmas (Andrade, Mozzer \& Oliveira, 2017).

Tendo em vista a importância do professor como mediador da construção de entendimentos pelos estudantes nas atividades fundamentadas em modelagem, ressaltamos a necessidade de que professores e futuros professores sejam encorajados a desenvolver conhecimentos sobre modelos, analogias e modelagem para que estejam aptos a utilizá-los adequadamente no ensino (Coll, 2006; Justi \& Van Driel, 2005; Oliveira \& Mozzer, 2017).

\section{A inibição enzimática e o seu ensino}

Milhares de diferentes tipos de proteínas podem ser encontradas em uma única célula, as quais são macromoléculas que controlam praticamente todos os processos biológicos. Dentre as diversas funções desempenhadas pelas proteínas, uma delas é a de atuar como catalisador de uma reação; neste caso, elas são chamadas de enzimas. A substância que reage com a enzima para formar um produto é denominada substrato da enzima. Existem moléculas capazes de interferir na catálise, reduzindo a velocidade ou 
interrompendo as reações das quais a enzima participa. Tais moléculas são denominadas inibidores enzimáticos (Nelson \& Cox, 2014; Patrick, 2013).

Em determinadas situações pode ser benéfico o impedimento do funcionamento de uma enzima; por exemplo, o da protease do vírus HIV. Esta é responsável por clivar as poliproteínas virais, formadas na célula infectada, em proteínas menores e funcionais, que serão fundamentais para que os novos vírus formados sejam capazes de infectar outras células (Nelson \& Cox, 2014; Patrick, 2013).

Um tipo comum de inibição da atividade enzimática ocorre através dos inibidores competitivos, os quais competem com o substrato pelo sítio ativo da enzima. Muitos inibidores dessa natureza fazem interações semelhantes àquelas que ocorrem entre o substrato e a enzima, o que permite a formação de um complexo enzima-inibidor estável (Nelson \& Cox, 2014).

No passado, pensava-se que um substrato se ligava ao sítio ativo da enzima de maneira semelhante a uma chave que trava uma fechadura - analogia chave-fechadura. Nesta analogia, o sítio ativo da enzima é comparado a uma fechadura, o substrato natural desta, a uma chave e o ato da chave ser capaz de destravar a fechadura, à conversão do substrato a produto (Patrick, 2013).

Ainda de acordo com esta analogia, o inibidor competitivo seria como a chave falsa, que apresenta propriedades estruturais mínimas, as quais permitem seu acesso à fechadura. A chave falsa, no entanto, não é capaz de permitir a abertura da porta. Tal comportamento poderia ser comparado à ação de um fármaco, que é capaz de ligar-se ao sítio receptor sem permitir a resposta biológica, uma vez que impede a entrada do substrato natural (Fraga, 2001).

Como pode ser observado, as relações de similaridade possibilitadas pela analogia chave-fechadura podem levar à inferência de que as moléculas possuem estruturas rígidas e que, portanto, existe um perfeito encaixe entre a enzima e o substrato. Em outras palavras, assim como uma única chave é capaz de abrir uma única fechadura, a reação catalisada seria eficiente apenas para o melhor substrato, isto é, aquele que se 'encaixasse' melhor na enzima. No entanto, esse cenário não explica como muitas enzimas são capazes de catalisar reações de diferentes substratos e aponta para uma séria limitação dessa analogia (Patrick, 2013).

Em geral, quando um ligante (substrato ou inibidor competitivo) se liga a uma enzima, ocorrem mudanças conformacionais (alteração no arranjo espacial dos átomos), que tornam o sítio de ligação mais complementar ao ligante, o que permite uma interação mais efetiva entre essas moléculas (Nelson \& Cox, 2014; Verli, \& Barreiro, 2005).

Para que os estudantes compreendam os fatores que levam uma proteína a apresentar determinada estrutura tridimensional, eles precisam reconhecer que o enovelamento da proteína é ocasionado por interações físicas intramoleculares (estabelecidas entre os resíduos de aminoácidos dentro da molécula) e intermoleculares (estabelecidas entre a proteína e as partículas do meio biológico). As principais forças não covalentes que são responsáveis por este processo são as interações de van der Waals, 
forças eletrostáticas e ligações de hidrogênio (Fraga, 2001; Nelson \& Cox, 2014).

Os modelos de ensino encontrados nos livros didáticos do ensino médio para explicar estes fenômenos são, muitas vezes, demasiadamente simplificados. A analogia chave-fechadura, por exemplo, na tentativa de explicar a especificidade da enzima que só atua com determinado(s) substrato(s), desconsidera um aspecto central da catálise enzimática: as interações químicas que ocorrem entre as moléculas. A falta de discussão em torno deste aspecto pode levar os estudantes a desenvolverem ideias equivocadas como, por exemplo, considerarem que as estruturas moleculares são rígidas. Para evitar incompreensões como esta, cuidados devem ser tomados pelos professores ao usarem estas ferramentas, de forma a garantir que os estudantes compreendam adequadamente os conceitos envolvidos e as limitações dos modelos e analogias (Sangiogo \& Zanon, 2012).

Considerando a complexidade das noções envolvidas no modelo consensualmente aceito para explicar o processo de inibição enzimática e os problemas no ensino do tema, desenvolvemos uma sequência didática sobre o processo de interação fármacoenzima fundamentada em modelagem. Essa sequência foi destinada a estudantes de um curso de Licenciatura em Química por considerarmos que o envolvimento de futuros professores com a modelagem pode contribuir para superar tais entraves e favorecer a promoção desta no ensino de Química.

\section{Modelos computacionais no ensino de Ciências}

O avanço dos recursos computacionais tem possibilitado a criação de modelos cada vez mais sofisticados para o planejamento de fármacos que satisfaçam as propriedades eletrônicas e estruturais para uma interação adequada com o sítio receptor (Rodrigues, 2001).

Mas o uso dos modelos computacionais não ocorre apenas na pesquisa. Eles são reconhecidos por professores de Química como uma ferramenta que favorece o ensino por diferentes motivos. Um deles, é permitir que os estudantes visualizem as moléculas a partir de vários modos de expressão, podendo auxiliar na compreensão de que uma mesma substância pode ser representada de diferentes maneiras. Outro motivo, é que o uso dos computadores permite trabalhar com macromoléculas, como polímeros e proteínas, ao passo que modelos concretos (como os de plástico) são mais difíceis de serem manipulados. O fato da modelagem molecular fornecer representações tridimensionais permite que elas sejam manipuladas e pode contribuir para que os estudantes melhorem suas percepções espaciais (Barnea \& Dori, 1996; 1999).

Esse último potencial é especialmente importante se considerarmos que, um dos desafios enfrentados pelos estudantes, é a necessidade de visualizar tridimensionalmente as representações bidimensionais das moléculas presentes nos livros didáticos. Em química, como em outros ramos da ciência, a visualização tridimensional é uma importante habilidade. Estudantes que não a possuem, geralmente, têm problemas em desenvolver seus entendimentos em tópicos como isomeria e geometria molecular 
(Barnea \& Dori, 1999).

As simulações computacionais têm potencial não apenas de ajudar os estudantes a compreender os fenômenos científicos, mas também de melhorar suas habilidades investigativas e de resolver problemas (Plass et al., 2012). Neste sentido, o estudo de Monaghan e Clement (2000) demonstrou que a experiência com a simulação computacional contribuiu para que estudantes conseguissem realizar simulações mentais, permitindo a eles resolver problemas análogos à situação que experimentaram no computador quando não estavam utilizando esse recurso.

Em um estudo recente Almeida e Kiill (2019) evidenciaram que uma proposta de ensino fundamentada em modelagem, usando modelos obtidos de uma impressora $3 \mathrm{D}$, possibilitou que os estudantes compreendessem que a interação enzima-substrato ocorre de forma dinâmica. Além dessa compreensão, o envolvimento dos estudantes na modelagem também favoreceu o entendimento de aspectos relacionados à natureza dos modelos; por exemplo, o fato de reconhecerem que eles têm limitações e que podem ser reformulados a partir de novas evidências.

Enquanto Almeida e Kiill (2019) basearam seu estudo na reflexão de estudantes de um curso de Licenciatura em Química sobre o uso de modelos tridimensionais concretos no processo de modelagem, nosso foco está no papel que os recursos computacionais dinâmicos e as analogias desempenham neste processo. Consideramos que a investigação desses outros recursos pode contribuir para o avanço da pesquisa na área, pois como Linenberger e Bretz (2014) advertem, as formas de representação dos modelos influenciam no entendimento dos conceitos envolvidos no ensino da temática interação enzima-ligante.

\section{Metodologia}

O entendimento conceitual dos estudantes ao longo do processo de ensinoaprendizagem foi investigado por meio de um estudo de caso, a partir do qual buscamos por evidências que nos permitissem fazer afirmações sobre nosso objetivo de pesquisa (Cohen et al., 2011). Apoiados nos pressupostos destes autores, consideramos que o estudo de caso possibilita uma compreensão profunda sobre o entendimento conceitual dos estudantes, na medida em que fornece um exemplo único de pessoas em situações reais de aprendizagem e considera as múltiplas variáveis envolvidas neste processo.

O caso por nós delimitado abarca um grupo de estudantes envolvidos em um conjunto de aulas fundamentadas nas etapas da modelagem. Nesta seção, apresentamos uma descrição das atividades vivenciadas pelos estudantes e, posteriormente, descrevemos a maneira como procedemos a coleta e a análise dos dados que compuseram o caso.

\section{Descrição das atividades}

As atividades desenvolvidas nas aulas foram elaboradas pelos autores com base nas recomendações de Justi (2006) de que os estudantes vivenciem as diferentes etapas do diagrama Modelo de Modelagem (Figura 1). Tais atividades foram apresentadas à 
professora da disciplina, que contribuiu com sugestões para aprimorá-las para aquele contexto de ensino.

Essas atividades, de cunho investigativo, propõem aos estudantes uma situaçãoproblema, na qual eles precisam decidir entre dois compostos (A e B), qual o melhor inibidor do ciclo de reprodução do vírus HIV. Para justificar tal escolha, os estudantes devem utilizar recursos da modelagem molecular na busca por evidências que a sustente.

A Figura 2 a seguir apresenta uma descrição resumida das atividades desenvolvidas em cada encontro, bem como a(s) principal(is) etapa(s) da modelagem associada(s) às atividades propostas (para maiores detalhes sobre a sequência didática, vide Martins, 2018). É importante ressaltar que o processo de modelagem é dinâmico e as etapas estão interligadas entre si (Gilbert \& Justi, 2016). Por isso, destacamos a etapa principal associada a cada atividade, mas isso não significa que as outras não ocorreram.

\begin{tabular}{|c|c|}
\hline Encontro/Descrição das atividades & $\begin{array}{l}\text { Etapa da } \\
\text { modelagem }\end{array}$ \\
\hline $\begin{array}{l}1^{\circ} \text { Encontro: Discussão, a partir de textos e slides, de vários aspectos sobre o vírus } \\
\text { HIV, como: formas de transmissão; fatores que podem contribuir para o aumento do } \\
\text { número de infectados; a maneira pela qual o corpo reage à infecção; como o HIV pode } \\
\text { levar ao desenvolvimento da AIDS; como o vírus utiliza as células humanas para se } \\
\text { multiplicar. } \\
\text { Solicitação da resolução de questões cujo objetivo principal é o levantamento de } \\
\text { hipóteses sobre a maneira pela qual os fármacos poderiam dificultar a reprodução do } \\
\text { vírus agindo nas estruturas que o constituem. }\end{array}$ & Criação \\
\hline $\begin{array}{l}2^{\circ} \text { Encontro: Explicação, a partir de um texto adaptado de um livro de bioquímica, } \\
\text { sobre o que são aminoácidos, como estes se ligam para formar proteínas e as diferentes } \\
\text { funções que estas macromoléculas podem exercer no organismo. } \\
\text { Solicitação de proposição de um modelo para representar um peptídeo, primeiro por } \\
\text { meio de desenho e, posteriormente, com bolas de isopor e palitos. }\end{array}$ & $\begin{array}{l}\text { Criação e } \\
\text { expressão }\end{array}$ \\
\hline $\begin{array}{l}3^{\circ} \text { Encontro: Adequação da geometria molecular do peptídeo levando em consideração } \\
\text { a Teoria de Repulsão dos Elétrons na Camada de Valência. } \\
\text { Solicitação de representação por meio de clips coloridos. Subsequente análise } \\
\text { de um gráfico de energia livre de uma proteína genérica em função do seu grau } \\
\text { de dobramento para reflexão sobre a existência de conformações mais estáveis e } \\
\text { solicitação de proposição de um modelo que represente o peptídeo na conformação } \\
\text { de menor energia. }\end{array}$ & Teste \\
\hline $\begin{array}{l}\text { Fornecimento de mapas de superfície de potencial eletrostático de alguns aminoácidos, } \\
\text { visando promover reflexões sobre a influência de regiões carregadas de uma molécula } \\
\text { em sua conformação. }\end{array}$ & \\
\hline $\begin{array}{l}4^{\circ} \text { Encontro: Apresentação de uma tabela com propriedades físico-químicas dos } \\
\text { aminoácidos, incluindo a solubilidade em meio aquoso. }\end{array}$ & \\
\hline $\begin{array}{l}\text { Solicitação de proposição de um modelo para a conformação de menor energia para } \\
\text { o peptídeo, levando em consideração as possíveis interações que podem ocorrer com } \\
\text { a água (solvente no meio intracelular). }\end{array}$ & Teste \\
\hline
\end{tabular}

Figura 2. Descrição das atividades e identificação da(s) etapa(s) da modelagem contempladas (continua) 


\begin{tabular}{|c|c|}
\hline Encontro/Descrição das atividades & $\begin{array}{l}\text { Etapa da } \\
\text { modelagem }\end{array}$ \\
\hline $\begin{array}{l}5^{\circ} \text { Encontro: Solicitação de levantamento de hipóteses sobre as diferentes maneiras } \\
\text { pelas quais um fármaco poderia atuar inibindo a atividade enzimática, a partir da } \\
\text { resolução de algumas questões. }\end{array}$ & $\begin{array}{l}\text { Criação e } \\
\text { expressão }\end{array}$ \\
\hline $\begin{array}{l}6^{\circ} \text { Encontro: Proposição de modelos, utilizando clips coloridos para explicar como os } \\
\text { compostos (A e B) poderiam atuar como inibidores da enzima HIV-1 protease, seguida } \\
\text { de discussão sobre o que é necessário para que um ligante seja um bom inibidor } \\
\text { competitivo. }\end{array}$ & $\begin{array}{l}\text { Criação e } \\
\text { expressão }\end{array}$ \\
\hline $\begin{array}{l}\text { 70 Encontro: Representação de um dos compostos via modelo computacional e ajuste } \\
\text { da conformação desta molécula via cálculo no software. } \\
\text { Interpretação dos resultados da simulação de ancoramento molecular, a partir da } \\
\text { visualização de como ocorre a interação de grupos do fármaco com a enzima e do } \\
\text { acesso ao valor de energia de interação para os diferentes compostos. }\end{array}$ & $\begin{array}{l}\text { Expressão e } \\
\text { teste }\end{array}$ \\
\hline 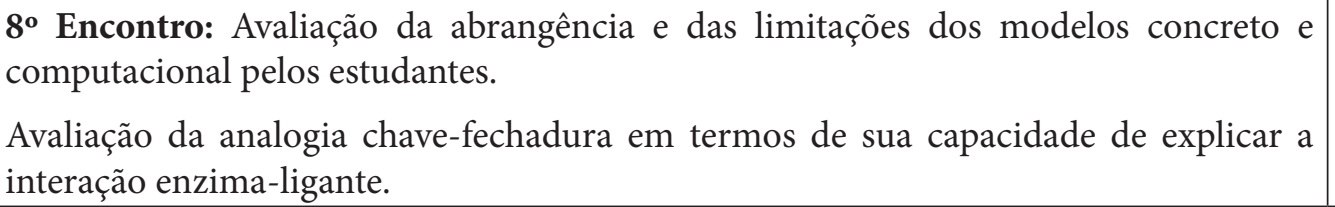 & Avaliação \\
\hline $\begin{array}{l}9^{\circ} \text { Encontro: Proposição e mapeamento de uma analogia para explicar a inibição } \\
\text { enzimática. } \\
\text { Produção de um texto justificando qual é o melhor inibidor teórico da enzima, com } \\
\text { base nas evidências disponibilizadas durante as atividades. }\end{array}$ & $\begin{array}{l}\text { Criação e } \\
\text { avaliação }\end{array}$ \\
\hline
\end{tabular}

Figura 2. Descrição das atividades e identificação da(s) etapa(s) da modelagem contempladas (continuação)

\section{Coleta e análise dos dados}

As atividades foram desenvolvidas com uma turma composta por seis estudantes do quinto período de um curso de Licenciatura em Química, de uma universidade federal situada no sudeste do Brasil. Todos os estudantes já haviam realizado discussões iniciais sobre modelos e modelagem e o papel destes na pesquisa e no ensino de Ciências, mas, até aquele momento, ainda não haviam vivenciado discussões formais sobre o uso de analogias nesses contextos.

O desenvolvimento das atividades em sala de aula foi guiado pelo primeiro autor deste trabalho. Neste contexto, ele era estudante do sétimo período de um curso de Licenciatura em Química e possuía familiaridade com os softwares que seriam utilizados, pois era bolsista de iniciação científica em um projeto na área de química computacional. A professora da disciplina, que é especialista em ensino fundamentado em modelagem no ensino de Ciências, acompanhou o pesquisador durante todo o desenvolvimento das atividades e fez intervenções em alguns momentos, no sentido de solicitar que os estudantes explicitassem ou esclarecessem suas ideias.

Durante a maior parte do desenvolvimento das atividades, os estudantes 
trabalharam em dois trios. Um dos grupos apresentou maior dificuldade de propor modelos próximos aos modelos curriculares durante o desenvolvimento das primeiras atividades. Por isso, diante do objetivo central dessa investigação, consideramos que a contribuição das atividades para evolução no entendimento conceitual dos integrantes desse grupo seria mais evidente. Esse motivo nos levou a escolhê-los como sujeitos de pesquisa.

O grupo estudado era composto por três integrantes do sexo feminino. Em observância aos princípios éticos, as estudantes leram e assinaram um termo de consentimento livre e esclarecido. Neste mesmo sentido, visando preservar a sua identidade, nomes fictícios foram atribuídos a elas neste estudo.

Um estudo de caso foi elaborado na tentativa de evidenciar o desenvolvimento do entendimento conceitual das estudantes ao longo das atividades de modelagem, focando nas atividades do quinto ao nono encontro, momento a partir do qual se iniciou a proposição de modelos para explicar, especificamente, a interação enzima-ligante.

Todas as aulas em que a sequência de ensino foi desenvolvida foram registradas em vídeo. A opção por esse tipo de registro se justifica em razão deste instrumento possibilitar a construção de dados mais fidedignos na tentativa de compreender os processos de ensino-aprendizagem, uma vez que os vídeos podem ser revistos quantas vezes forem necessárias na busca por evidências que sustentem as hipóteses da pesquisa (Carvalho, 2006). Para a realização das filmagens, utilizou-se duas filmadoras que foram, conforme a necessidade, posicionadas de maneiras diferentes com os objetivos de acompanhar as discussões ocorridas e de registrar a criação dos modelos.

A partir da visualização e análise de todas as filmagens, os trechos dos diálogos que forneciam evidências sobre o desenvolvimento do entendimento conceitual dos estudantes foram selecionados e transcritos. Nessas transcrições, quando necessário, foram adicionados comentários do pesquisador entre parênteses duplos para facilitar a compreensão dos diálogos.

O material escrito produzido pelos estudantes também foi recolhido para compor o corpo de dados desta pesquisa. Isso foi realizado em observância às recomendações de Cohen et al. (2011) de que múltiplas fontes de dados contribuem para uma maior validade do estudo de caso.

Para atingir nosso objetivo de pesquisa, primeiramente buscamos indícios de como a simulação computacional favoreceu a compreensão dos estudantes sobre o processo de inibição enzimática. Para isso, observamos as evoluções (ou involuções) nas compreensões conceituais ocorridas a partir da expressão dos modelos via simulação computacional.

Além disso, buscamos indícios do entendimento conceitual dos estudantes expresso quando eles criticaram a analogia da chave-fechadura e quando estes elaboraram uma nova analogia para representar o processo de inibição enzimática. Realizamos o mapeamento da analogia, tal como proposto por Mozzer e Justi (2015). Esse mapeamento foi disposto em quadros nos quais foram explicitados os domínios 
análogo e alvo comparados; e as relações de similaridade estabelecidas entre estes domínios (indicadas por setas bidirecionais).

A análise interpretativa das aulas foi discutida entre os autores deste trabalho em um processo de triangulação entre diferentes analistas (Cohen et al., 2011), visando estabelecer consensos quanto a mesma.

\section{Resultados e discussões}

Os modelos concretos produzidos pelas estudantes ao longo de todo o processo de modelagem foram elaborados levando-se em conta apenas um trecho da enzima protease do vírus HIV. Isso porque, considerando que uma proteína é uma macromolécula, seria muito difícil manipular os modelos caso toda a estrutura fosse levada em consideração.

Nos primeiros encontros $\left(2^{\circ}\right.$ ao $\left.4^{\circ}\right)$ foram estudados alguns fatores que podem influenciar a estrutura tridimensional que as macromoléculas podem assumir. Durante esses encontros, as estudantes propuseram modelos expressos por meio de desenhos, bolas de isopor e clips coloridos para modelar a estrutura da macromolécula. O objetivo destas atividades não era que as estudantes elaborassem um modelo para a estrutura tridimensional da molécula que fosse semelhante àqueles obtidos via difração de raios $\mathrm{X}$ ou cálculos computacionais; mas que propusessem modelos que representassem como as diferentes interações poderiam interferir na estrutura do peptídeo. Para isso, os modelos das estudantes foram submetidos a etapas de testes para favorecer que elas analisassem: (i) como os grupos funcionais da estrutura poderiam influenciar na conformação adotada pelo peptídeo, considerando as interações intramoleculares e intermoleculares; e (ii) a relação entre o estabelecimento destas interações com a energia do sistema.

Desta forma, quando se iniciaram as atividades de proposição de modelos para a interação da enzima com o fármaco ( $5^{\circ}$ encontro), as estudantes já haviam proposto um modelo para a estrutura do peptídeo. Assim, quando foram solicitadas a explicar, com base neste modelo, como seria a atuação do fármaco, elas disseram que o mesmo interagiria com a enzima, impedindo que ela se ligasse ao substrato natural e interrompendo a catálise. No entanto, para as estudantes, não haveria nenhuma mudança conformacional ou rompimento de interação intramolecular na proteína quando o inibidor se ligasse a ela.

O diálogo a seguir se refere ao momento do $5^{\circ}$ encontro em que as estudantes socializaram o modelo de interação do peptídeo com o composto A proposto:

Maria: Sabe por que eu acho que ele não muda ((se referindo à alteração na conformação do peptídeo))? Porque a gente já propôs um modelo em que ele está estável.

Pesquisador: Mas ele está estável naquele meio ((se refere ao sistema para o qual as estudantes haviam modelado a estrutura do peptídeo)).

Maria: Sim. E aí tem a água aqui ((faz gesto mostrando que haveria água ao redor do peptídeo)). 
Pesquisador: Mas se você mudar o meio?

Maria: Sim. Mas aí, acho que a energia seria maior. Iria desfazer interações aqui ((mostra os clipes que representam interações intramoleculares)).

O trecho evidencia que as estudantes não reconheciam que a presença do fármaco era uma condição de alteração do sistema. Para que haja a formação de um complexo enzima-inibidor estável, o ligante deve levar o sistema a um estado de menor energia (Patrick, 2013). Contudo, podemos notar que, para as estudantes, uma vez que a proteína estivesse em sua conformação mais estável, nenhuma mudança poderia ocorrer em sua estrutura. Dessa forma, elas evidenciaram atribuir rigidez à macromolécula e não reconhecer que a conformação de menor energia poderia variar se fosse realizada alguma alteração no sistema que levasse a um abaixamento de energia do mesmo.

O modelo concreto proposto pelas estudantes para a interação fármaco-enzima, referente ao composto B, está representado na Figura 3. A estrutura de clips menor (parte inferior da figura) representa o inibidor e a maior (parte superior), o peptídeo. Para as estudantes, o fármaco formaria interações do tipo ligação de hidrogênio com o peptídeo, onde antes estariam interagindo moléculas de água (as ligações de hidrogênio estão destacadas por círculos vermelhos na Figura 3).

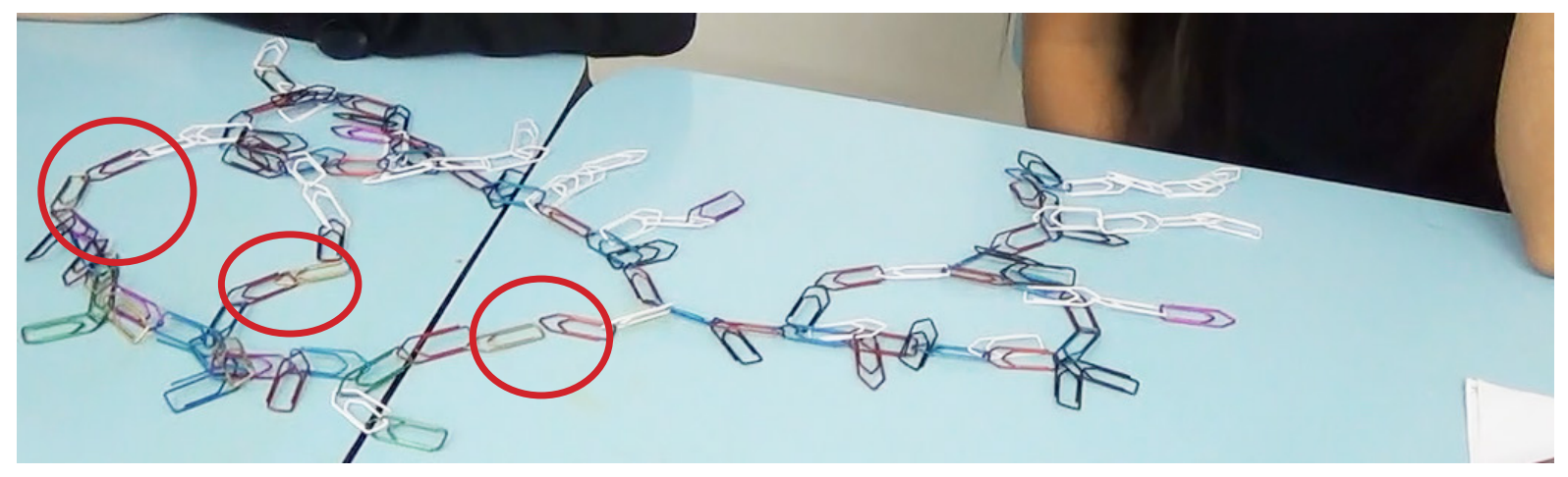

Figura 3. Modelo da interação do composto B com o peptídeo

Na sequência, as estudantes explicaram o motivo que as levou a propor o modelo de tal forma:

Maria: Aí quando eu coloco o composto... a gente acredita que o peptídeo não vai mudar de geometria.

Pesquisador: Por quê?

Cristina: A interação aquiéoxigênio-hidrogênio ((aponta para dois clipes que representam uma interação intramolecular do peptídeo)). E é a mesma daqui ((aponta para dois clipes que representam uma interação do peptídeo com o fármaco)). Aí, a gente colocou os hidrogênios que estão mais afastados para interagir com os oxigênios do peptídeo. E a gente viu que isso não ia afetar a geometria ((se refere à conformação do peptídeo)). 
Pesquisador: Mas eu vou fazer mais uma pergunta para vocês. Vocês acreditam que ele não rompe as interações que eles estão fazendo ((aponta para os grupos que fazem interação intramolecular no peptídeo)) para interagir com o fármaco?

\section{Maria: Anham!}

Pesquisador: Mas você concorda que a água estava interagindo aqui? ((O pesquisador afasta um clipe que representa uma interação intermolecular entre o peptídeo e o composto e aponta para o clipe que representa função carboxi do composto)).

Maria: Sim.

Pesquisador: Aí, para que esse interagisse aqui ((o pesquisador mostra novamente um dos clips que representam a interação intermolecular entre o fármaco e o peptídeo)), $a$ água teve que deixar de interagir.

Cristina: Anham! Foi.

Maria: Foi.

Pesquisador: Então, interações foram rompidas quando você coloca o fármaco.

Cristina: Mas a gente falou de interação dele com ele mesmo ((se refere às interações intramoleculares do peptídeo)).

As estudantes reconheciam que a presença do inibidor alteraria interações préexistentes no sistema, pois interações do tipo ligação de hidrogênio do peptídeo com a água seriam rompidas para que o fármaco pudesse interagir com o mesmo. Mas, para elas, interações intramoleculares no peptídeo não poderiam ser alteradas. As estudantes não apresentaram uma justificativa que desse suporte para explicar porque certas interações poderiam ser rompidas ao passo que outras não, uma vez que em ambos os casos se tratavam de ligações do tipo ligação de hidrogênio.

Em uma das perguntas da folha de atividades, as estudantes foram questionadas se, com base nos modelos concretos elaborados, seria possível prever qual seria o melhor inibidor da enzima HIV-1 protease. A resposta do grupo, expressa por escrito, foi a seguinte:

"Sim; O composto B, pois através do modelo, percebemos que o composto B pode ter o maior número de interações intermoleculares com o peptídeo do que o composto A. Essas interações ocorrem entre o átomo de oxigênio e o átomo de hidrogênio, sendo o átomo de oxigênio carregado parcialmente negativamente e o átomo de $\mathrm{H}$ carregado parcialmente positivamente, fazendo com que haja uma interação entre ambos."

Embora as estudantes tenham explicado corretamente como ocorria a interação de hidrogênio para o sistema que estavam analisando, elas atribuíram a característica de melhor inibidor ao composto que faria um maior número de interações, preocupandose, neste caso, com a quantidade de interações e não com a intensidade das mesmas. 
Além disso, apesar de termos encontrado a resposta acima na folha de atividades, a ideia de que seria possível decidir qual o melhor inibidor não era consensual entre as integrantes do grupo, como mostra a transcrição a seguir:

Maria: Ô Pesquisador, eu acho difícil decidir só com esse modelo. Teria que usar algum outro tipo de modelo.

Pesquisador: Então tente convencer a Cristina aí.

Maria: Aqui a gente não consegue representar todos os tipos de interação... Qual é a resposta certa, Pesquisador?

Pesquisador: Ter resposta certa é ótimo! É um modelo, vocês têm que argumentar.

Maria: Eu posso utilizar um outro modelo?

Pesquisador: Calma aí! É com esse modelo. Com o que vocês já propuseram até agora.

Maria: Com esse modelo eu acho que a gente não consegue.

Pesquisador: ((Inaudível)) você não estaria utilizando esse modelo?

Maria: Se esse modelo não desse para explicar, você não estaria utilizando esse ((risos)), não é?

Pesquisador: Não sei!

Maria: Te peguei! ((Risos)).

Pesquisador: Eu posso acreditar que com esse modelo não dá para resolver, mas você pode me apresentar uma argumentação que é extremamente satisfatória para me convencer de que com esse modelo você consegue decidir. Entendeu?

\section{Maria: Anham!}

Pode-se notar que Maria estava insatisfeita com o modelo, mesmo acreditando que, se com o modelo de clipes não fosse possível decidir, o pesquisador não teria apresentado essa proposta para a turma. Isso motivou a estudante a questionar sobre outras formas de expressar o modelo.

Conforme discutido por Gilbert e Justi (2016), a seleção de modos de representação adequados é um aspecto chave para a expressão do modelo e este processo é influenciado, principalmente, pelos propósitos para o qual o modelo foi pensado e pela natureza dos elementos a serem modelados. Nesse sentido, a insatisfação de Maria com o modelo proposto realça que as limitações daquele modelo não permitiam a representação de aspectos importantes que possibilitassem decidir qual seria o melhor inibidor.

Dessa forma, com o objetivo de sustentar a ideia de Maria de que, com os 
modelos propostos, seria inviável saber qual o melhor inibidor, o pesquisador iniciou uma discussão relacionando quantidade de energia à força da interação, a partir de uma representação do diagrama de poço potencial que ele fez no quadro. Aspectos dessa discussão foram considerados pelas estudantes, como mostra o seguinte trecho retirado de uma resposta escrita presente na folha de atividades do grupo:

"Para a avaliação do melhor inibidor teórico da protease viral, deveríamos ter os valores de energia referentes as interações, pois assim, poderíamos saber quais interações são mais fortes as que liberam mais energia."

Cristina completou a resposta oralmente, dizendo que precisariam usar outra forma de expressar os modelos que lhes possibilitasse a consideração de mais dados. A proposição de se utilizar softwares para contornar as limitações da representação concreta elaborada veio da outra integrante do grupo, Maria. Ela alegou que, por meio destes, seria possível calcular a energia de interação e que as geometrias dos átomos seriam mais fiéis. Neste momento é evidente que as estudantes realizaram alguns processos que são apontados por Rea-Ramirez et al. (2008) como fundamentais para a elaboração de modelos com maior poder explicativo: a busca por novas formas de expressar a interação enzima-ligante, motivada pelas limitações identificadas nos modelos, a insatisfação com o modelo já proposto e a divergência de ideias quanto à abrangência do modelo.

Orientadas pelo pesquisador, as estudantes representaram no computador um modelo de bolas e varetas da estrutura de um dos compostos usando o software Spartan Pro ${ }^{\circ}$ Em seguida, foi solicitado que realizassem uma simulação de minimização de energia. Nesta, puderam observar os átomos se movendo à medida em que sofriam alterações no ângulo de ligação, ligações químicas giravam e alguns grupos se aproximavam ou afastavam. A partir disso, foi discutido o porquê de o composto ter mudado de conformação (o programa ajustou a conformação da molécula para um estado de menor energia), bem como os fatores que o programa levava em consideração ao fazer esse cálculo, tais como: os efeitos de repulsão estérica e as possíveis interações atrativas intramoleculares.

Posteriormente, o pesquisador explicou como funcionava o software Molegro Virtual Docker, em que iriam realizar a ancoragem molecular ${ }^{1}$, enfatizando que seria necessário deixar os resíduos de aminoácidos do sítio ativo da enzima flexíveis para se moverem de forma a fazer possíveis interações com o fármaco durante a simulação. Até esse momento, as estudantes não haviam considerado a flexibilidade dos resíduos de aminoácidos na macromolécula; por isso, ele foi importante para fornecer evidências que as estimulariam a fazer uma análise crítica do modelo que haviam proposto e a reformulá-lo. De acordo com Mendonça e Justi (2013), a reflexão sobre a plausibilidade de ideias/informações inconsistentes com as ideias defendidas pode levar os estudantes a realizar modificações no seu modelo.

1 Processo que consiste basicamente em posicionar um ligante de diferentes formas dentro do sítio ativo da enzima e associar um valor de energia a cada uma dessas poses (Patrick, 2013). 
Nessa fase das atividades, as estudantes puderam observar, por meio do modelo computacional, as diferentes poses adotadas pelos compostos dentro do sítio ativo da enzima e os valores de energia associados em decorrência dos grupos que estavam interagindo naquelas poses. A pose de menor energia para um dos compostos é apresentada na Figura 4.

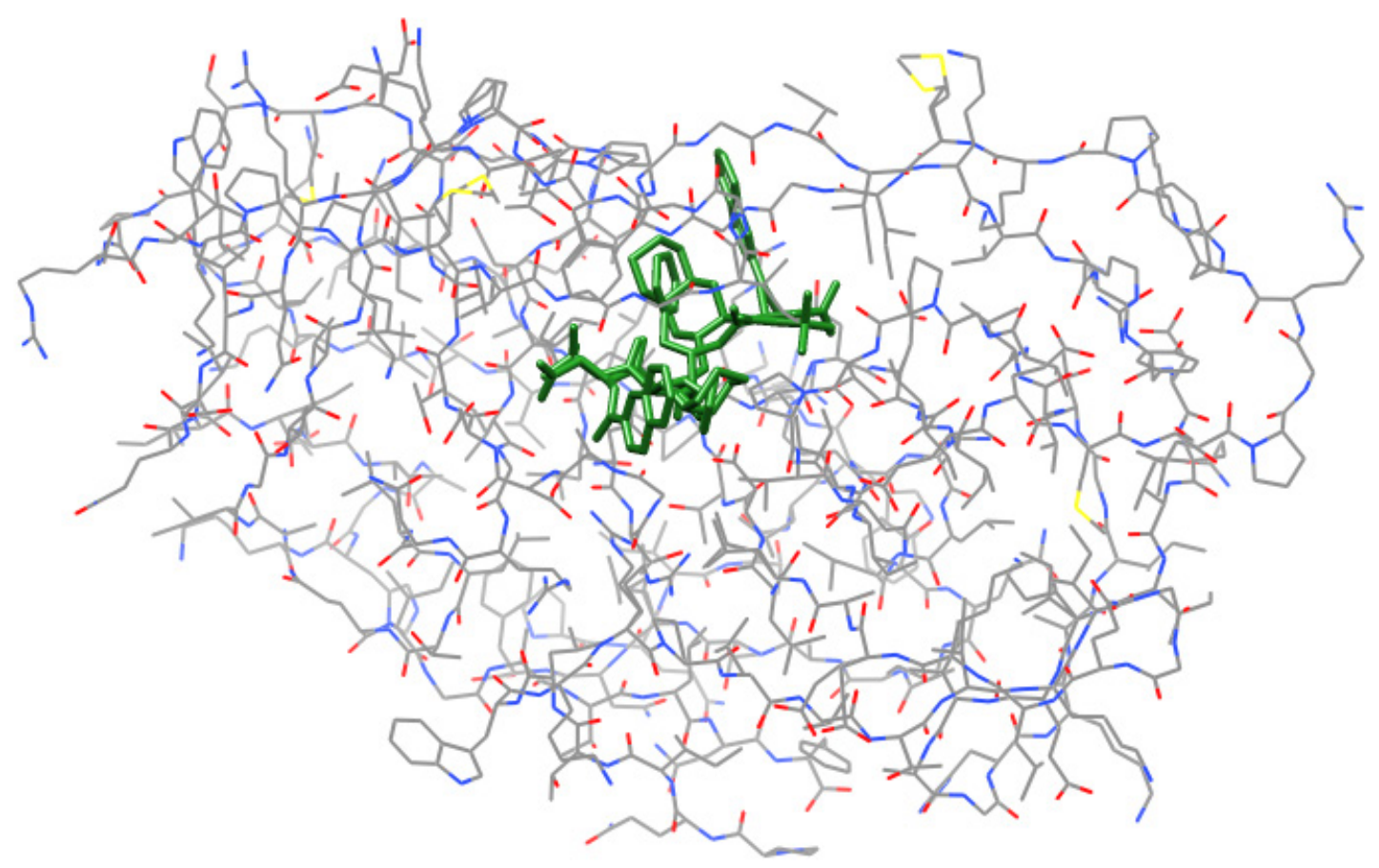

Figura 4. Estrutura da HIV-1 protease com um inibidor (em verde) no seu sítio ativo

No encontro posterior, foi solicitado a elas que explicassem o motivo da enzima apresentar diferentes conformações entre sua forma ligada e não ligada ao inibidor. $\mathrm{O}$ trecho a seguir ilustra o início da discussão desse aspecto:

Maria: Ô Pesquisador, nessa letra A aqui ((lê a questão "a que se deve a alteração da conformação?"))... foi aquilo que no final da aula a gente fez eh;; Colocou lá o menor... A gente apertou aquele negócio da energia e mudou a conformação.

Pesquisador: Então você está falando que tem a ver com a energia?

Maria: $\hat{E}$.

Pesquisador: Mas essa alteração da conformação, no caso, é alteração da enzima.

Maria: Isso.

O diálogo acima mostra que Maria se lembrou da simulação de minimização de energia que, embora tenha sido realizada para a estrutura tridimensional do inibidor e não da enzima, foi importante para que ela associasse a mudança de conformação na enzima com o abaixamento da energia. Desse modo, pode-se inferir que tal simulação 
foi importante para que as estudantes compreendessem que a presença do inibidor causaria uma mudança conformacional na macromolécula e que isto alteraria a energia do sistema. Essa inferência é suportada pela resposta escrita fornecida pelas estudantes para a questão na folha de atividades:

"Ao adicionar o fármaco, ele interage com a enzima, de modo que ela alcance a maior estabilidade, ou seja, menor energia, fazendo com que a enzima tenha uma outra conformação".

Após a discussão da questão anterior, o pesquisador questionou as estudantes se seria possível propor um modelo para interação fármaco-enzima que levasse em conta as mudanças conformacionais das moléculas, utilizando, para isso, os clipes disponibilizados. As estudantes responderam afirmativamente e explicaram que, uma vez que esse recurso possibilitava a representação de uma estrutura flexível, poderia ter sido utilizado, mas que, quando propuseram o modelo inicial, não reconheciam essa possibilidade.

Essa evolução no entendimento conceitual das estudantes foi possível devido aos recursos computacionais terem funcionado como testes para o modelo. A simulação de minimização de energia e as discussões em torno da preparação da enzima para o cálculo de ancoramento molecular forneceram evidências que possibilitaram a análise crítica pelas estudantes de aspectos do modelo proposto, contribuindo para que elas realizassem reformulações no mesmo (Gilbert \& Justi, 2016).

As estudantes também reconheceram os aspectos adicionais do alvo que o modelo computacional permitia representar em relação aos modelos concretos que foram propostos, como ilustra a seguinte transcrição da resposta presente na folha de atividades:

"O modelo concreto é plano, isso dificulta de observar a geometria, e no modelo computacional é mais fácil visualizar a interação do fármaco com a enzima. No modelo computacional podemos variar os tipos de modelo para representar a enzima."

Após a leitura desta resposta pelas estudantes, o pesquisador solicitou-lhes alguns esclarecimentos:

Pesquisador: Mas por que que ele era plano?

Maria: Porque a gente mantinha ele em uma única posição ((faz gesto passando a mão sobre a mesa)).

Pesquisador: Por causa da dificuldade com o material?

Cristina: Sim.

Maria: De manuseio também.

Pesquisador: Sim. O que mais vocês acham? 
Maria: No modelo concreto também tem a questão que a gente reduzia os grupos...

Cristina: Para não ficar muito grande ((faz gesto passando a mão sobre a mesa)).

Pesquisador: Para facilitar a visualização?

Cristina: $E^{\text {. }}$

Maria: E no modelo computacional tem como colocar ((se refere aos átomos que eram representados no modelo computacional, diferentemente dos modelos de clipes, em que às vezes um clip representava grupos de átomos)).

Cristina: A gente colocou que no modelo computacional é mais fácil visualizar a interação do fármaco com a enzima, né? Igual a gente viu essa conformação aqui que a gente nem tinha pensado nisso ((se refere a mudança conformacional da proteína ao interagir com o fármaco)). E que no modelo computacional a gente pode variar o tipo de modelo, de bolinha...

Pesquisador: Certo.

Professora da turma: Variar as formas de representação do modelo?

Cristina: É, as formas de representar o modelo.

Pesquisador: $O$ modelo que vocês haviam proposto dá conta de explicar a questão da energia da interação? O concreto?

Cristina: Eu acho que não.

Maria: Não.

Pesquisador: Não dava para calcular a energia.

Maria: É. E até também a questão da interação que, como a gente não conseguia observar a geometria em específico, às vezes o que a gente colocava para interagir não interagiria por conta da geometria... Talvez ele interagisse em outro lugar que fosse mais favorável.

As estudantes reconheceram potencialidades do modelo computacional como a visualização da interação fármaco-enzima, devido à representação da distribuição dos átomos no espaço de forma mais detalhada que no modelo concreto, o qual dava a impressão de uma molécula plana. Além disso, elas destacaram a possibilidade de transitar entre diferentes formas de expressão, algo considerado por Gilbert, Queiroz e Justi (2010) como fundamental para o desenvolvimento da capacidade de visualização pelos estudantes.

Os recursos da simulação computacional que, como observaram Barnea e Dori (1996), permitem que se trabalhe com moléculas grandes mantendo os comprimentos e os ângulos de ligação mais precisos quando comparados aos modelos concretos, 
contribuíram para uma melhor percepção da estrutura tridimensional da molécula pelas estudantes.

Em relação aos aspectos que o modelo concreto e o computacional davam conta de explicar, as integrantes do grupo destacaram que, em ambas as formas de expressão, era possível variar as cores, facilitando a diferenciação dos átomos ou grupos de átomos, o que possibilitava que ambos os modelos pudessem ser utilizados para refletir sobre possíveis interações que poderiam ocorrer entre as moléculas.

Dando continuidade às atividades, o pesquisador apresentou a analogia chavefechadura, expressa da seguinte forma: "O complexo enzima-substrato (ES) se assemelha a um sistema de encaixe, semelhante ao de chave-fechadura; basta o reagente (S) ser um pouco diferente, para que o encaixe não seja possível e a reação não seja realizada" (Feltre, 2004, p. 370). Em seguida, ele solicitou que as estudantes identificassem e mapeassem as relações de similaridade e as limitações dessa comparação.

Para as estudantes, a analogia poderia ser utilizada para explicar dois aspectos principais: o primeiro deles refere-se à questão funcional, isto é, cada enzima pode interagir com moléculas específicas, assim como chaves específicas abrem determinadas fechaduras (Junior, 2009); o segundo aspecto é o fato da interação ocorrer entre grupos específicos, ou seja, assim como cada dente da chave se encaixa em uma determinada cavidade, átomos do inibidor interagem em regiões específicas dentro do sítio ativo da enzima.

O trecho transcrito a seguir refere-se ao momento em que o pesquisador solicitou que as estudantes explicitassem o que elas estavam chamando de interações durante a discussão sobre as relações de similaridade da analogia:

Cristina: Os. dentes da chave encaixar...

Maria: Dentes da chave encaixando com os dentes lá dentro.

Cristina: Não sei se a...

Pesquisador: Se vocês fossem comparar isso com o domínio alvo, vocês poderiam falar assim oh;; assim como os dentes da chave se encaixam nas regiões especificas da fechadura, o fármaco...

Cristina: Igual tipo. Você coloca lá o hidrogênio interagindo lá com oxigênio. Aí beleza. Você vai colocar o oxigênio interagindo com sei lá... um outro átomo lá. Sei lá. É a mesma coisa que você tentar colocar a chave de cabeça para baixo.

Maria: E tem a questão também de que a chave correta tem o encaixe perfeito. Todos os grupos...

Maria: Todos os grupos são encaixados.

Estudante do outro grupo: Mas dá a ideia de que todos os grupos estão interagindo com a enzima. 
Maria: No caso isso seria uma limitação. Mas não que...

Cristina: A gente colocou como limitação.

Maria: Não que esse modelo não explicaria... não deixaria de explicar a interação.

As estudantes consideraram como correspondente às interações do domínio alvo, o contato físico entre os dentes da chave e as cavidades da fechadura no domínio análogo. Quando indagadas pela estudante do outro grupo sobre essa comparação dar a ideia de que todos os grupos do fármaco estariam, necessariamente, interagindo com a enzima, as estudantes alegaram que esta seria uma limitação da analogia.

No entanto, em momentos futuros elas repensaram o domínio análogo e passaram a considerar que esta não seria uma limitação da analogia chave-fechadura, como evidencia a resposta fornecida por escrito na folha de atividades:

"Pensando na chave como um todo, há apenas uma parte que entra na fechadura, essa seria a parte do fármaco que interage com a enzima. Já a parte da chave que fica para fora da fechadura seria a parte do fármaco que não interage com a enzima, sendo a enzima a fechadura. Isso explica que as interações entre o fármaco e a enzima existem, mas o fármaco não interage totalmente, não se encaixa na fechadura, do mesmo jeito que outra chave (outro fármaco) não se encaixaria na fechadura, não faria tantas interações com a enzima."

Nota-se na resposta anterior que as estudantes reconheceram que diferentes fármacos vão agir com diferentes intensidades para inibir uma enzima dependendo das interações que estes poderão fazer com a macromolécula, sendo este um aspecto importante a ser considerado ao se estudar os inibidores competitivos (Patrick, 2013). A análise dos dados de ancoramento molecular, a partir dos quais puderam observar que tanto o número de interações, quanto a energia da interação são diferentes para os inibidores $\mathrm{A}$ e $\mathrm{B}$, pode ter dado suporte à construção desse modelo explicativo mais elaborado pelas estudantes.

Entre as limitações destacadas, elas reconheceram que a chave e a fechadura seriam estruturas rígidas como é evidenciado na fala de uma das estudantes:

Maria: A enzima muda de conformação já a fechadura não vai mudar de conformação devido a presença da chave. E a chave, assim como a fechadura, não muda sua conformação.

$\mathrm{Na}$ perspectiva de ensino fundamentado em modelagem reconhecer que as analogias possuem limitações é um processo importante, pois assim como os modelos não são cópias da entidade modelada, não existe um análogo capaz de estabelecer relações de similaridade com todos os aspectos do domínio alvo (Mozzer \& Justi, 2015).

A partir de considerações feitas pelas estudantes ao longo da aula, foi possível montar o quadro expresso na Figura 5, com o mapeamento das relações de similaridade identificadas pelas estudantes nessa etapa de avaliação da analogia: 


\begin{tabular}{|l|l|l|}
\hline \multicolumn{1}{|c|}{$\begin{array}{c}\text { Análogo } \\
\text { (Chave-fechadura) }\end{array}$} & Mapeamento & \multicolumn{1}{|c|}{$\begin{array}{c}\text { Domínio alvo } \\
\text { (Interação fármaco-enzima) }\end{array}$} \\
\hline $\begin{array}{l}\text { A chave tem dentes que interagem com } \\
\text { a fechadura. }\end{array}$ & & $\begin{array}{l}\text { Os grupos do fármaco e da enzima } \\
\text { interagem quimicamente. }\end{array}$ \\
\hline $\begin{array}{l}\text { A chave tem uma parte que não } \\
\text { 'interage' com a fechadura (o lugar de } \\
\text { segurar a chave). }\end{array}$ & $\begin{array}{l}\text { Existem grupos no fármaco que não } \\
\text { interagem com a enzima. }\end{array}$ \\
\hline $\begin{array}{l}\text { Uma chave que entra pela metade, não } \\
\text { irá interagir tão bem com a fechadura. }\end{array}$ & $\begin{array}{l}\text { Um fármaco com poucos grupos } \\
\text { que interagem com a enzima, não irá } \\
\text { interagir tão bem com a mesma. }\end{array}$ \\
\hline
\end{tabular}

Figura 5. Mapeamento da analogia chave-fechadura identificados pelas estudantes

Após a análise crítica da analogia chave-fechadura foi solicitado às estudantes que elaborassem uma analogia para explicar a interação entre um ligante e a enzima. $\mathrm{O}$ momento da socialização dessa comparação encontra-se transcrito a seguir:

Maria: É uma roda de dança de...

Carla: Dança de quadrilha.

Maria: Aí, no caso, todas as pessoas que estão participando, estão dando as mãos nessa roda. Aí, essa roda estaria em correspondência com a enzima antes do fármaco atuar. Porque aí, no caso, ela teria uma conformação. Aí tem o noivo e a noiva no meio dessa roda. Isso estaria em comparação na hora que o fármaco estaria na parte ativa da enzima. Aí na hora que os noivos vão entrar, o narrador da quadrilha fala "viva os noivos!". Neste momento a roda vai em direção aos noivos que estão no centro, que seria a parte que o fármaco e a enzima iriam se interagir. Aí tem pessoas que não vão conseguir chegar ao centro. Aí essa parte seria os grupos que não fazem interação. E as mãos dadas para o alto ((ergue os braços juntos para o alto com as mãos fechadas)) seria as interações que o fármaco faria... que a enzima faria com ela mesma, e alguns iriam conseguir interagir diretamente com o fármaco, que seria a parte da interação do fármaco com a enzima, que seria dos noivos com as pessoas da roda. Aí, de limitação que a gente tem é que homem e mulher, mas não são só dois elementos que constituem a enzima e o fármaco, isso seria uma limitação.

Pesquisador: Se vocês pensarem um pouco mais na analogia podem perceber que isso não é uma limitação.

Cristina: Por quêe?

Pesquisador: Pensa aí! Acho que isso pode não ser uma limitação se você pensar que têm vários homens e várias mulheres.

Maria: Sim. Porque eles vão estar caracterizados de forma diferente. 
Pesquisador: E isso aí pode ser o quê? Pensando na enzima?

Maria: Os grupos. Aí a limitação de que depois... tipo assim... que depois de acabarem de interagir com os noivos eles voltam para a roda normal, mas isso não acontece com o fármaco e a enzima porque eles não deixam de se interagir.

Pesquisador: Será?! O que a gente discutiu? Que o fármaco, ele não fica lá para sempre no sítio ativo da enzima.

Maria: Ele vai saindo aos poucos.

Pesquisador: Ele entra e depois ele sai.

Maria: $E_{\text {. }}$

Pesquisador: Tanto que a pessoa tem que ficar tomando o medicamento diariamente.

A partir dessa discussão e com base nas relações que elas expressaram na folha de respostas, foi feito o mapeamento da analogia (Figura 6):

\begin{tabular}{|l|l|l|}
\hline \multicolumn{1}{|c|}{$\begin{array}{c}\text { Análogo } \\
\text { (Roda de quadrilha) }\end{array}$} & Mapeamento & \multicolumn{1}{c|}{$\begin{array}{c}\text { Domínio alvo } \\
\text { (Interação fármaco-enzima) }\end{array}$} \\
\hline $\begin{array}{l}\text { A roda muda de conformação para as } \\
\text { pessoas interagirem com os noivos. }\end{array}$ & & $\begin{array}{l}\text { A enzima muda de conformação } \\
\text { para os grupos interagirem com o } \\
\text { fármaco. }\end{array}$ \\
\hline $\begin{array}{l}\text { Em uma roda de quadrilha todos as } \\
\text { pessoas se movem livremente }\end{array}$ & $\begin{array}{l}\text { O fármaco e a enzima têm grupos } \\
\text { de átomos flexíveis }\end{array}$ \\
\hline $\begin{array}{l}\text { Há pessoas que não conseguem chegar } \\
\text { ao centro da roda para interagir com os } \\
\text { noivos. }\end{array}$ & $\begin{array}{l}\text { Há grupos da enzima que não } \\
\text { interagem com o fármaco. }\end{array}$ \\
\hline
\end{tabular}

Figura 6. Mapeamento da analogia roda de quadrilha

Antes da aula em que trabalharam com a simulação computacional, o modelo expresso pelas estudantes não levava em consideração possíveis mudanças conformacionais na enzima. A análise das relações de similaridade expressas na Figura 6, por outro lado, nos permite afirmar que houve evolução no entendimento conceitual, pois na analogia elaborada, elas elucidaram esse aspecto por meio da relação de similaridade com a mudança na configuração da roda de quadrilha para a interação com os noivos.

A protease do vírus HIV possui uma estrutura quaternária formada por duas subunidades. Cada cadeia polipeptídica possui uma extremidade carboxiterminal e outra aminoterminal, por isso, podemos dizer que cada subunidade possui duas extremidades (Nelson \& Cox, 2014; Patrick, 2013). As estudantes destacaram como limitação o fato da roda de quadrilha não possuir extremidades, uma vez que as pessoas dariam as mãos formando um círculo. Dessa forma, elas apontaram apenas uma dissemelhança entre um elemento do análogo (a roda de quadrilha) e outro do alvo (a enzima), mas não identificaram nenhuma limitação da comparação com o conceito alvo (interação entre 
ligante e enzima). Exemplos de possíveis limitações são: a diferença entre a natureza das interações (físicas e eletrostáticas) nos domínios comparados ou o fato de que diferentes fármacos poderiam interagir de formas diferentes com a enzima (na roda de quadrilha têm-se um mesmo par de noivos para interagir com a roda). Esta última limitação envolve um aspecto importante da compreensão sobre a interação entre fármaco e enzima que não foi considerado pelas estudantes na analogia.

Quando questionadas sobre qual composto seria o melhor inibidor teórico da enzima com base nas atividades vivenciadas, elas responderam o seguinte:

Cristina: Então. A gente colocou que no início a gente estava pensando no $B$, só que com o modelo computacional ficou muito mais fácil a visualização de que era o A, pela estabilidade que ele apresentou.

Pesquisador: Como vocês sabem a estabilidade?

Cristina: Pelo cálculo de energia que foi possível fazer dentro do programa.

Podemos notar na justificativa de Cristina que o valor da energia de interação foi um fator decisivo na escolha do composto. As estudantes já haviam compreendido em aulas anteriores que o melhor inibidor seria aquele que interagisse mais fortemente com a protease, e que esse tipo de interação ocorreria quando as interações atrativas fossem maximizadas e as interações repulsivas minimizadas, sendo que os modelos computacionais possibilitavam esse cálculo de energia e o modelo concreto não.

\section{Conclusões}

A partir de um estudo de caso, nos propusemos a investigar o desenvolvimento no entendimento conceitual sobre o processo de formação do complexo fármaco-enzima, de estudantes de um curso de Licenciatura em Química, a partir de uma sequência de ensino fundamentada na modelagem. Mais especificamente, buscamos compreender os papéis desempenhado pelos modelos computacionais e pelos processos de crítica e de elaboração de analogias na compreensão conceitual sobre o tema.

Este trabalho corrobora com outros existentes na literatura (Almeida \& Kiill, 2019; Maia \& Justi, 2009; Mozzer et al., 2007; Sousa \& Justi, 2010) que evidenciam o potencial da modelagem em possibilitar a evolução do entendimento conceitual dos estudantes. No contexto investigado, essa evolução conceitual foi favorecida pela utilização de modelos computacionais, os quais foram essenciais para que as estudantes incorporassem novas características ao seu modelo inicial, tornando-o mais coerente com as ideias científicas. Em outras palavras, a evolução no entendimento conceitual proporcionada pelos recursos computacionais ocorreu, principalmente, porque eles funcionaram como teste dos modelos fornecendo evidências que possibilitaram a reformulação dos mesmos.

Este avanço no entendimento conceitual promovido pelo uso dos recursos computacionais decorre do fato de que eles possibilitaram que múltiplas variáveis 
fossem consideradas em relação às estruturas químicas estudadas como: geometria dos átomos no espaço, ângulos de ligação e interações intra e intermoleculares. Essas características tornam os modelos computacionais importantes instrumentos de ensino, quando sistemas complexos, como aqueles envolvendo macromoléculas são estudados (Barnea \& Dori, 1996; 1999).

As estudantes reconheceram, após o uso dos recursos computacionais, que o modelo inicial expresso a partir de clips coloridos, não considerava a possibilidade de alterações conformacionais e dava a ideia de que as estruturas moleculares eram planas. Já os modelos computacionais permitiram a visualização da estrutura tridimensional das macromoléculas, o que facilitou a compreensão das estudantes de como ocorre a interação e o cálculo da energia de interação para os inibidores, aspecto apontado por elas como fundamental para a previsão do melhor inibidor teórico da enzima.

Esses conhecimentos foram evidenciados também quando as estudantes realizaram uma análise crítica da analogia chave-fechadura. Neste processo, elas destacaram que: (i) o fármaco e a enzima não são estruturas rígidas como a chave e a fechadura, reconhecendo que há alteração da conformação destas estruturas químicas; e (ii) as interações ocorrem devido a presença de diferentes grupos, ao comparar os átomos com os dentes da chave e as cavidades da fechadura (Martins et al., 2019).

A análise crítica da analogia chave-fechadura permitiu que as estudantes reconhecessem que esta não leva em consideração as mudanças conformacionais que podem ocorrer durante o processo de inibição de uma enzima pelo fármaco. Em função disso, as estudantes elaboraram uma nova comparação entre a dinâmica de uma roda de quadrilha e as mudanças conformacionais envolvendo a formação do complexo enzimaligante, a partir da qual foram capazes de explicar esse aspecto.

Assim, nosso estudo corrobora o que foi evidenciado pela literatura da área: a elaboração de analogias pelos estudantes pode favorecer a aprendizagem do domínio alvo na medida em que, neste processo criativo, eles podem selecionar um domínio análogo que lhes é realmente familiar e, a partir dele, explicitar relações de similaridade coerentes (Mozzer \& Justi, 2015; 2018).

A identificação de limitações na analogia de autoria das estudantes, no entanto, não teve o êxito esperado. Isso pode ter ocorrido devido ao fato de que, ao se concentrarem na elaboração de relações de similaridade que explicassem aspectos do alvo vistos como essenciais, as estudantes tenham relegado para um segundo plano, a identificação das limitações de sua comparação, uma vez que reconheceram apenas a existência de simples diferenças físicas entre o análogo e o alvo (roda fechada e cadeia aberta). Tal fato nos faz atentar para a necessidade de que o professor não só solicite que os estudantes identifiquem as limitações da analogia, mas também que os oriente na identificação de aspectos não comparáveis entre os domínios alvo e análogo (Mozzer \& Justi, 2015).

Em suma, esse estudo evidenciou que os modelos computacionais forneceram evidências que permitiram que as estudantes se atentassem a aspectos importantes do processo estudado até então desconsiderados e, com isso, compreendessem o sistema 
estudado em um maior grau de complexidade. Tais compreensões foram manifestadas, principalmente, quando as estudantes compararam o modelo concreto com $\mathrm{o}$ computacional e quando participaram de um processo de crítica e criação de analogias. Esse último ponto nos permite afirmar que as analogias podem atuar não só como modelos de ensino ou fonte de ideias dentro do processo de modelagem (Clement, 2008; Mozzer \& Justi, 2018; Oliva \& Aragón, 2009), mas também como fontes de evidências do entendimento conceitual dos estudantes neste processo.

Esses resultados reforçam a consideração de que a aprendizagem no ensino fundamentado em modelagem é influenciada pelas formas de expressão dos modelos (Louca \& Zacharia, 2012). Neste sentido, realçamos a importância de que futuros professores possam vivenciar processos de ensino semelhantes ao que foi descrito neste estudo, os quais possam contribuir para fomentar reflexões sobre os diferentes recursos de expressão de modelos, suas potencialidades e limitações, ao planejarem e desenvolverem propostas de ensino fundamentadas em modelagem.

Além disso, considerando-se a contribuição dos modelos computacionais para o entendimento dos estudantes sobre processos de natureza complexa e dinâmica como o que lidamos neste estudo, novas pesquisas poderiam ser propostas no sentido de investigar em que medida a modelagem computacional possibilitaria uma compreensão mais ampla dos estudantes sobre a natureza desses modelos como artefatos humanos que apoiam pensamento. Isso porque, como Gilbert e Justi (2016) destacam, pesquisas de áreas como a Filosofia e a Educação têm focado no papel dos modelos de representar a entidade modelada, mas poucas são aquelas que exploram seu papel na produção de conhecimentos e que assumem a representação como uma atividade mediadora e criativa, como assumimos neste trabalho.

Neste mesmo sentido, ao realçar o sucesso das estudantes na análise crítica da analogia chave-fechadura em relação a que elas propuseram, o presente estudo nos permite supor que a vivência do processo de modelagem pode ter possibilitado que as estudantes não assumissem o modelo do livro didático como um "argumento de autoridade" com base na confiança na fonte da informação (Jiménez-Aleixandre, 2010). Isso aponta para a necessidade de se investigar melhor se e como a modelagem pode influenciar a compreensão dos estudantes sobre a natureza das analogias.

\section{Agradecimentos}

Agradecemos ao CNPq, à CAPES e à FAPEMIG pelo financiamento e bolsas que possibilitaram a realização desta pesquisa. Agradecemos também aos professores Dr. John K. Gilbert (in memoriam) e Dra. Rosária Justi pela obra que inspirou a idealização e a condução desta pesquisa e por suas significativas contribuições para a área de Educação em Ciências; e aos avaliadores, cujos comentários e críticas nos auxiliaram na produção deste documento. 


\section{Referências}

Almeida, J. F., \& Kiill, K. B. (2019). Modelagem tridimensional: Reflexões de futuros professores de Química para o ensino e aprendizagem da interação enzima-substrato. Investigações em Ensino de Ciências, 24(3), 282-304. https://dx.doi.org/10.22600/15188795.ienci2019v24n3p282

Andrade, G. M. P. C., Mozzer, N. B., \& Oliveira, T. M. A. (2017). O papel dos questionamentos do professor em atividades fundamentadas em modelagem analógica. Enseñanza de las Ciencias, (Extraordinário), 4535-4540.

Barnea, N., \& Dori, Y. J. (1996). Computerized Molecular Modelling as a Tool To Improve Chemistry Teaching. Journal of Chemical Information and Computer Sciences, 36(4), 629-636. https://doi.org/10.1021/ci950122o

Barnea, N., \& Dori, Y. J. (1999). High-School Chemistry Students' Performance and Gender Differences in a Computerized Molecular Modelling Learning Environment. Journal of Science Education and Technology, 8(4), 257-271. https://doi. org/10.1023/A:1009436509753

Carvalho, A. M. P. (2006). Uma metodologia de pesquisa para estudar os processos de ensino e aprendizagem em salas de aula. In F. M. T. Santos, \& I. M. Greca. (Eds.), A pesquisa em ensino de ciências no Brasil e suas metodologias (pp. 13-48). Editora Unijuí.

Chittleborough, G. D., \& Treagust, D. F. (2009). Why Models are Advantageous to Learning Science. Educación Química, 20(1), 12-17. https://doi.org/10.1016/S0187893X(18)30003-X

Clement, J. (2008). Creative Model Construction in Scientists and Students: The role of imagery, analogy and mental simulations. Dordrecht: Springer.

Cohen, L., Manion, L., \& Morrison, K. (2011). Research Methods in Education. 7. ed. Routledge.

Coll, R. K., France, B., \& Taylor, I. (2005). The role of models/and analogies in science education: implications from research. International Journal of Science Education, 27(2), 183-198. https://doi.org/10.1080/0950069042000276712

Coll, R. K. (2006). The role of models, mental models and analogies in chemistry teaching. In P. Aubusson, A. Harrison, \& S. M. Ritchie. (Eds.), Metaphor and analogy in science education (pp. 65-77). Springer.

Duit, R. (1991). On the role of analogies and metaphors in learning science. Science Education, 75(6), 649-672. https://doi.org/10.1002/sce.3730750606

Feltre, R. (2004). Química: Química Orgânica. 6. ed. Moderna.

Fraga, C. A. M. (2001). Razões da atividade biológica: interações micro- e biomacromoléculas. Química Nova na Escola, cadernos temáticos, (3), 33-42. 
Gentner, D. (1983). Structure-mapping: A theoretical framework for analogy. Cognitive Science, 7(2), 155-170. https://doi.org/10.1016/S0364-0213(83)80009-3

Gilbert, J. K. (2004). Models and modelling: routes to more authentic science education. International Journal of Science and Mathematics Education, 2(2), 115-130. https://doi. org/10.1007/s10763-004-3186-4

Gilbert, J., \& Justi, R. (2016). Modelling-based teaching science education. Springer.

Glynn, S. M. (1991). Explaining science concepts: a teaching-with-analogies model. In S. M. Glynn, R. H. Yearny, \& B. K. Britton. (Eds.), The Psychology of Learning Science (pp. 219-240). Lawrence Erlbaum.

Grosslight, L., Unger, C., Jay, E. e Smith, C. L. (1991). Understanding models and their use in science: conceptions of middle and high school students and experts. Journal of research in science teaching, 28(9), 799-822. https://doi.org/10.1002/tea.3660280907

Harrison, A. G, \& Treagust, D. F. (2000) A typology of school science models. International JournalofScienceEducation,22(9),1011-1026.https://doi.org/10.1080/095006900416884

Jiménez-Aleixandre, M. P. (2010). 10 ideas clave: Competencias en argumentación y uso de pruebas. Graó.

Johnson-Laird, P. N. (1983). Mental Models. MIT Press.

Junior, W. E. F. (2009). Analogias em livros didáticos de química: Um estudo das obras aprovadas pelo Plano Nacional do Livro Didático Para o Ensino Médio 2007. Ciências \& Cognição, 14(1), 121-143.

Justi, R. (2006). La enseñanza de ciencias basada en la elaboración de modelos. Enseñanza de las Ciencias, 24(2), 173-184.

Justi, R. (2019) Modelos e modelagem no ensino de química: Um olhar sobre aspectos essenciais pouco discutidos. In W. L. P. dos Santos, \& O. A. Maldaner. (Eds). Ensino de Química em Foco, 2. ed, (pp. 175-193). Editora Unijuí.

Justi, R, \& Gilbert, J. (2002). Modelling, teachers' views on the nature of modelling, and implications for the education of modellers. International Journal of Science Education, 24(4), 369-387. https://doi.org/10.1080/09500690110110142

Justi, R., \& Van Driel, J. (2005). The development of science teachers' knowledge on models and modelling: Promoting, characterizing, and understanding the process. International Journal of Science Education, 27(5), 549-573. https://doi. org/10.1080/0950069042000323773

Knuuttila, T. (2005). Models as epistemic artefacts: Toward a non-representationalist account of scientific representation. University of Helsinki.

Linenberger, K. J., \& Bretz, S. L. (2014). Biochemistry students' ideas about shape and charge in enzyme-substrate interactions. Biochemistry and Molecular Biology Education, 42(4), 366-367. https://doi.org/10.1002/bmb.20776 
Louca, L. T., \& Zacharia, Z. C. (2012). Modeling-based learning in science education: cognitive, metacognitive, social, material and epistemological contributions. Educational Review, 64(4), 471-492. https://doi.org/10.1080/00131911.2011.628748

Maia, P. F., \& Justi, R. (2009). Learning of Chemical Equilibrium through Modellingbased Teaching. International Journal of Science Education, 31(5), 603-630. https://doi. org/10.1080/09500690802538045

Martins, D. M. (2018). O desenvolvimento do entendimento conceitual sobre ainteração fármaco-enzima em uma sequência de ensino fundamentada na modelagem eno uso de recursos computacionais. (Trabalho de Conclusão de Curso). Departamento de Química da Universidade Federal de Ouro Preto, Ouro Preto.

Martins, D. M., Mozzer, N. B., Caetano, M. S. (2019). A Compreensão do Processo de Interação Fármaco-enzima na Crítica e Elaboração de Analogias Durante uma Sequência de Ensino Fundamentada na Modelagem. In Anais do XII Encontro Nacional de Pesquisa em Educação em Ciências. Natal, Brasil.

Mendonça, P. C. C., \& Justi, R. (2013). The Relationships Between Modelling and Argumentation from the Perspective of the Model of Modelling Diagram. International Journal of Science Education, 35(14), 2407-2434. https://doi.org/10.1080/09500693.201 3.811615

Monaghan, J. M., \& Clement, J. (1999). Use of a computer simulation to develop mental simulations for understanding relative motion concepts. International Journal of Science Education, 21(9), 921-944. https://doi.org/10.1080/095006999290237

Mozzer, N. B., \& Justi, R. (2015). Nem tudo que reluz é ouro: Uma discussão sobre analogias e outras similaridades e recursos utilizados no ensino de Ciências. Revista Brasileira de Pesquisa em Educação em Ciências, 15(1), 123-147.

Mozzer, N. B, \& Justi, R. (2018). Modelagem Analógica no Ensino de Ciências. Investigações em Ensino de Ciências, 23(1), 155-182. http://dx.doi.org/10.22600/15188795.ienci2018v23n1p155

Mozzer, N. B., Queiroz, A. S., \& Justi, R. (2007). Proposta de Ensino de Introdução ao Tema Interações Intermoleculares via Modelagem. In Anais do VI Encontro Nacional de Pesquisa em Educação em Ciências. Florianópolis, SC.

Nelson, D. L., \& Cox, M. M. Princípios de bioquímica de Lehninger. 6 ed. Editora Artmed.

Oliva, J. M., \& Aragón, M. M. (2009). Contribución del aprendizaje con analogías al pensamiento modelizador de los alumnos en ciencias: marco teórico. Enseñanza de las Ciencias, 27(2), 195-208.

Oliveira, T. M. A., \& Mozzer, N. B. (2017). Análise dos Conhecimentos Declarativo e Procedimental de Futuros Professores de Química sobre Analogias. Ensaio: Pesquisa em Educação em Ciências, 19(e2602), 1-24. https://doi.org/10.1590/1983-21172017190102 
Orgill, M., \& Bodner, G. (2004). What research tells us about using analogies to teach Chemistry. Chemistry Education Research and Practice, 5(1), 15-32. https://doi. org/10.1039/B3RP90028B

Patrick, G. L. (2013). An Introduction to Medicinal Chemistry. 5. ed. United Kingdom: Oxford University Press.

Plass, J., Milne, C., Homer, B. D., Schwartz, R. N., Hayward, E. O., Jordan, T., ... Barrientos, J. (2012). Investigating the effectiveness of computer simulations for chemistry learning. Journal of Research in Science Teaching, 49(3), 394-419. https://doi.org/10.1002/tea.21008

Rea-Ramirez, M. A., Clement J., \& Núñez-Oviedo M. C. (2008). An Instructional Model Derived from Model Construction and Criticism Theory. In J. Clement, \& M. A. ReaRamirez (Eds.), Model Based Learning and Instruction in Science: Models and Modelling in Science Education (pp. 23-43). Springer.

Rodrigues, C. R. (2001). Processos modernos no desenvolvimento de fármacos: modelagem molecular. Química Nova na Escola, cadernos temáticos, (3), 43-49.

Sangiogo, F. A., \& Zanon, L. B. (2012). Reflexões sobre modelos e representações na formação de professores com foco na compreensão conceitual da catálise enzimática. Química Nova na Escola, 34(1), 26-34.

Silva, T. A., Oliveira, T. M. A, \& Mozzer, N. B. (2017). Modelagem analógica na abordagem do equilíbrio químico. In F. M. Mazzé, M. G. L. da Silva, \& M. T. Barroso (Org.), Propostas e Materiais Inovadores para o Ensino de Química (pp. 13-51). Editora Livraria da Física.

Sousa, V. C. A., \& Justi, R. (2010). Estudo da utilização de modelagem como estratégia para fundamentar uma proposta de ensino relacionada à energia envolvida nas transformações químicas. Revista Brasileira de Pesquisa em Educação em Ciências, 10(2).

D. F., Chittleborough, G. D., \& Mamiala, T. L. (2004). Students' Understanding of the Descriptive and Predictive Nature of Teaching Models in Organic Chemistry. Research in Science Education, 34, 1-20. https://doi.org/10.1023/B:RISE.0000020885.41497.ed

Verli, H., \& Barreiro, E. J. (2005). Um paradigma da química medicinal: A flexibilidade dos ligantes e receptores. Química Nova, 28(1), 95-102. https://doi.org/10.1590/S010040422005000100018 
Diego Magno Martins

https://orcid.org/0000-0002-6272-5643 Universidade Federal de Minas Gerais

Instituto de Ciências Exatas

Departamento de Química

Belo Horizonte, Minas Gerais, Brasil diegomartins838@yahoo.com.br

Nilmara Braga Mozzer

https://orcid.org/0000-0002-2060-7964

Universidade Federal de Ouro Preto Instituto de Ciências Exatas e Biológicas

Departamento de Química Ouro Preto, Minas Gerais, Brasil nilmara@ufop.edu.br

Thais Mara Anastácio Oliveira

https://orcid.org/0000-0001-6907-6335

Universidade Federal de Ouro Preto Instituto de Ciências Humanas e Sociais Programa de Pós-graduação em Educação Mariana, Minas Gerais, Brasil thais-moliveira@hotmail.com

Melissa Soares Caetano

${ }^{0}$ https://orcid.org/0000-0002-3522-5424

Universidade Federal de Ouro Preto Instituto de Ciências Exatas e Biológicas

Departamento de Química Ouro Preto, Minas Gerais, Brasil melissa.soares@ufop.edu.br

Submetido em 25 de maio de 2020

Aceito em 24 de julho de 2020

Publicado em 25 de agosto de 2020 